\title{
Protective effects of SS31 on t-BHP induced oxidative damage in $661 \mathrm{~W}$ cells
}

\author{
WEI MA ${ }^{1}$, XIAOBO ZHU $^{1}$, XIAOYAN DING ${ }^{1}$, TAO LI $^{1}$, YIJUN HU $^{1}$, XUTING HU $^{2}$,

 \\ ${ }^{1}$ State Key Laboratory of Ophthalmology, Zhongshan Ophthalmic Center, Sun Yat-Sen University, Guangzhou, Guangdong 510060; \\ ${ }^{2}$ Department of Retinal Surgery, The School of Ophthalmology and Optometry, Eye Hospital, Wenzhou Medical College, \\ Wenzhou, Zhejiang 325027; ${ }^{3}$ Department of Opthalmology, First Affiliated Hospital of Kunming Medical College, \\ Kunming, Yunnan 650032, P.R. China
}

Received August 18,2014; Accepted April 24, 2015

DOI: $10.3892 / \mathrm{mmr} .2015 .4055$

\begin{abstract}
The present study aimed to investigate the ability of SS31, a novel mitochondria-targeted peptide to protect against t-BHP-induced mitochondrial dysfunction and apoptosis in $661 \mathrm{~W}$ cell lines. The $661 \mathrm{~W}$ cells were treated with various concentrations of SS-31 and an MTT assay was used to determine cell viability. The expression of nitrotyrosine and 8-hydroxydeoxyguanosine (8-OHdG) was detected using immunofluorescent staining. Apoptosis were assessed using Hoechst staining and an annexin V/propidium iodide flow cytometer. Reactive oxygen species (ROS) were detected using MitoSOX ${ }^{\mathrm{TM}}$ with confocal microscopy. Changes in mitochondrial membrane potential were analyzed using flow cytometry. In addition, the release of cytochrome $c$ was analyzed using confocal microscopy. The viability of the cells improved following treatment with SS31 between $100 \mathrm{nM}$ and $1 \mu \mathrm{M}$, compared with untreated control group. Compared with the t-BHP treatment group $(20.0 \pm 3.8 \%)$, the number of annexin $\mathrm{V}$-positive cells decreased dose-dependently to $13.6 \pm 2.6$, $9.8 \pm 0.5$ and $7.4 \pm 2.0 \%$ in the SS-31 treated group at concentrations of $10 \mathrm{nM}, 100 \mathrm{nM}$ and $1 \mu \mathrm{M}$, respectively. Treatment with SS-31 significantly prevented the t-BHP-induced expression of nitrotyrosine and $8-\mathrm{OHdG}$, decreased the quantity of mitochondrial ROS, increased mitochondrial potential, and prevented the release of cytochrome $c$ from mitochondria into the cytoplasm. Therefore, the SS31 mitochondria-targeted peptide protected the $661 \mathrm{~W}$ cells from the sustained oxidative stress induced by t-BHP.
\end{abstract}

Correspondence to: Professor Shibo Tang or Professor Yan Luo, State Key Laboratory of Ophthalmology, Zhongshan Ophthalmic Center, Sun Yat-Sen University, 54 Xianlie Road, Guangzhou, Guangdong 510060, P.R. China

E-mail: tangshibo@vip.163.com

E-mail: luoyan2@mail.sysu.edu.cn

Key words: retinal degeneration, photoreceptor, oxidative stress, in vitro, neuroprotection, antioxidants

\section{Introduction}

Apoptosis of photoreceptors leads to retinal dysfunction in retinal degenerative diseases, including retinitis pigmentosa (RP), however, the exact mechanism remains to be elucidated $(1,2)$. Measurements using oxygen electrodes in a RCS rat model of RP have revealed that oxidative stress may be involved in the pathogenesis of photoreceptor degeneration, whereas, oxidative damage in the outer retina in a transgenic pig model results in gradual cone cell death, and administration of a cocktail of antioxidants reduces markers of oxidative damage in cones and reduces cone cell death in rd1 mice (3-5). Oxidative stress also triggers the apoptosis of photoreceptors in vitro, and antioxidants prevent oxidative stress-induced apoptosis of photoreceptors (6).

Mitochondria are known to be a major source of intracellular reactive oxygen species (ROS) and are particularly vulnerable to oxidative stress. Increasing evidence suggests that ROS are key in promoting the release of cytochrome $c$ from the mitochondria $(7,8)$, and cytochrome $c$ in the cytoplasm triggers a series of apoptotic signal transduction processes, resulting in apoptotic cell death $(9,10)$. It appears promising to target mitochondrial oxidative stress using antioxidant therapy, however, there are several difficulties in developing and using antioxidative drugs, in the delivery of drugs to the mitochondria, minimization of adverse effects and delivering drugs across the blood-retina barrier (11).

SS31 is a cell-permeable mitochondria-targeted antioxidant peptide. Previous studies have demonstrated that SS31 selectively partitions to the inner mitochondrial membrane, where it scavenges ROS generated by the electron transport chain. In addition, studies have revealed that SS31 can prevent the $\mathrm{Ca}^{2+}$-induced mitochondrial permeability transition (MPT) and release of cytochrome $c(11,12)$. Several animal investigations have demonstrated that SS31 may be beneficial in models of ischemia/reperfusion-induced myocardial infarction (13), brain infarction, Alzheimer's disease (AD) and amyotrophic lateral sclerosis (ALS) (13-16). However, it whether SS31 has a protective effect on retinal degenerative diseases by attenuating oxidant injury to photoreceptor cells remains to be elucidated. Therefore, in the present study, the 
effects of SS31 on t-BHP-induced mitochondrial dysfunction and oxidative damage in $661 \mathrm{~W}$ photoreceptor cells were investigated.

\section{Materials and methods}

Cell culture. The $661 \mathrm{~W}$ cell line used in the present study was provided by Dr Muayyad Al-Ubaidi (University of Oklahoma, Norman, USA). These cells were cultured in Dulbecco's modified Eagle's medium (DMEM; Gibco, NY, USA), supplemented with $10 \%$ fetal calf serum (Sigma-Aldrich, St. Louis, $\mathrm{MO}, \mathrm{USA}$ ) at $37^{\circ} \mathrm{C}$ in a humidified $5 \% \mathrm{CO}_{2}$ atmosphere. In all the following assays, $661 \mathrm{~W}$ cells were cultured at a density of $2 \times 10^{5}$ in growth medium for $24 \mathrm{~h}$ at $37^{\circ} \mathrm{C}$ prior to the treatment. When grown to $75-80 \%$ confluence, the cells were incubated with different concentrations of t-BHP (Sigma-Aldrich), either alone, or in the presence of SS31 depending on the experimental requirements. In all experiments, control cells were cultured without any treatment.

Cell viability assay. To determine the viability of the cells subsequent to oxidative stress, the $661 \mathrm{~W}$ cells were seeded into 96-well plates and treated with t-BHP $(25,50,100,200$ or $400 \mu \mathrm{M})$, with or without $\mathrm{SS} 31(10,100 \mathrm{nM}$ or $1 \mu \mathrm{M})$ for $24 \mathrm{~h}$, rinsed once in PBS, then incubated with serum-free DMEM containing $0.25 \mathrm{mg} / \mathrm{ml}$ MTT (Sigma-Aldrich). After $4 \mathrm{~h}$, the MTT solution was aspirated, dimethyl sulfoxide $(0.1 \mathrm{ml} /$ well $)$ was added, and the plates were shaken for $10 \mathrm{~min}$ at room temperature. The optical densities of the supernatant were read at $490 \mathrm{~nm}$ using a microplate spectrophotometer (Spectra Max 340; Molecular Devices, Sunnyvale, CA, USA). The results were obtained from four independent experiments. The optical density of the formazan formed in the control cells was considered as $100 \%$ viability.

Detection of protein and DNA peroxidation. To examine the antioxidative role of SS31, nitrotyrosine and 8-hydroxydeoxyguanosine $(8-\mathrm{OHdG})$ were used as markers of lipid and DNA peroxidation, respectively, to detect oxidative damage. These markers were detected by immunofluorescence using mouse anti-nitrotyrosine antibody (mouse monoclonal; 1:200; cat. no. ab7048; Abcam, Cambridge, MA, USA) and goat anti-8-OHdG antibody (goat polyclonal; 1:200; cat. no. AB5830; Chemicon, Temecula, CA, USA). The $661 \mathrm{~W}$ cells were seeded at a density of $2 \times 10^{5}$ and grown in culture dishes for 1 day. The cells were subsequently treated with $100 \mathrm{mM}$ t-BHP for $24 \mathrm{~h}$ in the absence or presence of $100 \mathrm{nM} \mathrm{SS31}$. The cells were fixed with freshly prepared 4\% formaldehyde in PBS for $10 \mathrm{~min}$, washed with phosphatebuffered saline (PBS), permeabilized with $0.1 \%$ Triton X-100 in PBS for 2 min, and rinsed with PBS. Following blockade of the non-specific binding sites by incubation with blocking buffer (PBS and 5\% BSA) for $60 \mathrm{~min}$, the cells were incubated with the primary antibodies overnight at $4^{\circ} \mathrm{C}$. The cells were then rinsed thoroughly with PBS and were incubated with anti-mouse immunoglobulin (Ig)G-Alexa 555 and anti-goat IgG-Alexa 555 secondary antibodies (donkey polyclonal; 1:3,000; cat. no. A21292; Invitrogen Life Technologies) for $1 \mathrm{~h}$. Following repeated washing twice with PBS, the slides were mounted and analyzed using a Zeiss LSM 510 META confocal microscope (LSM510 META; Carl Zeiss, Oberkochen, Germany). Fluorescence images were captured using identical exposure settings. For the negative control, the sections were stained without primary antibodies to produce no fluorescent signals.

Determination of cell apoptosis using Hoechst staining. Apoptosis was determined using Hoechst staining in the 661w cells treated with $100 \mu \mathrm{M}$ t-BHP, and without or with $100 \mathrm{nM}$ SS31 for $24 \mathrm{~h}$. Nuclear integrity was evaluated following staining of the cell nuclei using Hoechst, a fluorescent dye that binds to DNA. Briefly, the cells were permeated using $0.1 \%$ Triton X-100 in PBS, washed with PBS, and incubated with $0.05 \%$ Hoechst for $10 \mathrm{~min}$. The cells were considered to be apoptotic when they exhibited either fragmented or condensed nuclei. To quantitatively analyze the changes of nuclear morphology, the percentage of cells with apoptotic nuclei was then calculated. The results were obtained from 10 randomly-selected fields per sample in four independent experiments with microscopy (Zeiss, Jena, Germany).

Flow cytometry for the measurement of apoptosis. The presence of apoptotic cells was evaluated by an early change in membrane phospholipid asymmetry associated with cells during the early phases of apoptosis. The loss of cell membrane phospholipid asymmetry is accompanied by the exposure of phosphatidylserine to the outer membrane (17). Apoptosis was assessed in the present study using an Annexin V/Propidium Iodide (PI) kit, according to the manufacturer's instructions (Bender Med Systems, Vienna, Austria). The 661w cells were treated with $100 \mu \mathrm{M}$ t-BHP without or with $10 \mathrm{nM}, 100 \mathrm{nM}$ or $1 \mu \mathrm{M} \mathrm{SS} 31$ for $24 \mathrm{~h}$. Briefly, $4 \times 10^{5}$ cells were removed from the culture dishes by 3 min incubation in $0.05 \%$ trypsin. The $661 \mathrm{~W}$ cells were washed twice with PBS and resuspended in $185 \mu 1$ $1 \mathrm{X}$ binding buffer. Subsequently, $5 \mu \mathrm{l}$ annexin $\mathrm{V}$ and $10 \mu 1 \mathrm{l}$ PI were added to the cell suspension, which was then vortexed and incubated for $15 \mathrm{~min}$ in the dark at room temperature. Finally, $200 \mu \mathrm{l} 1 \mathrm{X}$ binding buffer was added, and the samples were evaluated using flow cytometry (FASC Aria II SORP; BD Bioscience, San Jose, CA, USA). In total 20,000 cells were analyzed per sample. Cells, which were negative for PI and annexin V staining were live cells; PI-negative, annexin $\mathrm{V}$-positive cells were early apoptotic cells; and PI-positive, annexin V-positive cells were primarily cells in the late stages of apoptosis.

Detection of ROS. Intra-mitochondrial production of ROS in the live cells was estimated fluorimetrically using MitoSOX Red (Invitrogen Life Technologies). Briefly, the cells were treated with $100 \mu \mathrm{M} \mathrm{t}$-BHP for $1 \mathrm{~h}$ at $37^{\circ} \mathrm{C}$, with or without $100 \mathrm{nM}$ SS31. Subsequently, the $661 \mathrm{~W}$ cells were loaded with the MitoSOX Red fluorogenic probe $(5 \mu \mathrm{mol} / \mathrm{l})$ for $20 \mathrm{~min}$. Following removal of MitoSOX Red and washing of the cells with Hanks' balanced salt solution, fluorescent images were captured using a confocal microscope. The mean fluorescence intensity per $\mathrm{mm}^{2}$ cell area was calculated using Zeiss software (Carl Zeiss).

Measurement of mitochondrial membrane potential $(\Delta \Psi m)$. JC-1, a $\Delta \Psi \mathrm{m}$ indicator, was used to demonstrate the changes 
in $\Delta \Psi \mathrm{m}$ in the $661 \mathrm{~W}$ cells. JC-1 is a lipophilic and cationic dye, which permeates plasma and mitochondrial membranes. The dye fluoresces red when it aggregates in the matrix of healthy, high $\Delta \Psi \mathrm{m}$ mitochondria, whereas it exhibits green fluorescence in cells with low $\Delta \Psi \mathrm{m}$ (18). The JC-1 (Invitrogen Life Technologies) was freshly diluted in serum-free DMEM to a final concentration of $1 \mu \mathrm{g} / \mathrm{ml}$ and was added to the treated and non-treated cells at densities of $1 \times 10^{6}$ cells $/ \mathrm{ml}$. Following incubation for $20 \mathrm{~min}$ at $37^{\circ} \mathrm{C}$ in the dark, the samples were rinsed twice in PBS and analyzed immediately using flow cytometry. Data were collected at $525 \mathrm{~nm}$ emission for green fluorescence and $590 \mathrm{~nm}$ for red fluorescence. The ratio of the red:green (aggregate:monomer) fluorescence intensity values was used to assess the $\Delta \Psi \mathrm{m}$.

Measurement of the release of cytochrome $c$. The release of cytochrome $c$ is a putative event of the mitochondria apoptotic pathway following the loss of $\Delta \Psi \mathrm{m}$. To evaluate whether cytochrome $c$ (mouse polyclonal; 1:300; cat. no. sc4198; Santa Cruz Biotechnology, Inc., Santa Cruz, CA, USA) was released from the mitochondria, immunocytochemical labeling of cytochrome $c$ was performed using confocal microscopy. The $661 \mathrm{~W}$ cells were treated with $100 \mathrm{mM}$ t-BHP either alone, or with $100 \mathrm{nM} \mathrm{SS} 31$ for $24 \mathrm{~h}$. The cells were immunolabeled with mouse monoclonal anti-cytochrome $c$ and rabbit anti-HSP60 antibodies (rabbit polyclonal; 1:500; cat. no. sc2714; Santa Cruz Biotechnology, Inc.) at room temperature overnight, followed by incubation with anti-mouse IgG-Alexa 555 (donkey polyclonal; 1:3,000; cat. no. A21292; Invitrogen Life Technologies) and anti-rabbit IgG-Alexa 488 secondary antibodies for $1 \mathrm{~h}$ subsequent to thorough rinsing twice with PBS. Cells were then washed and mounted in fluorescence mounting medium. For negative control, sections stained without primary antibodies showed no signals.

Statistical analysis. Statistical analysis was performed using SPSS 13.0 analytical software (SPSS, Inc., Chicago, MO, USA). All assays were performed in at least three separate experiments. Data are presented as the mean \pm standard error of the mean and were evaluated using one-way analysis of variance. $\mathrm{P}<0.05$ was considered to indicate a statistically significant difference.

\section{Results}

SS31 prevents the decrease in $661 \mathrm{~W}$ cell viability induced by oxidative damage. The viability of the $661 \mathrm{~W}$ cells was reduced following exposure to t-BHP for $24 \mathrm{~h}$ in a dose-dependent manner. Marked cytotoxicity was observed at concentrations of $\geq 100 \mu \mathrm{M} \mathrm{t}$-BHP, compared with the untreated control cells (Fig. 1A). As shown in Fig. 1B, treatment of the 661W cells with t-BHP at $100 \mu \mathrm{M}$ for $24 \mathrm{~h}$ led to $\sim 30 \%$ loss of cell viability $(\mathrm{P}<0.01 ; \mathrm{n}=4)$. By contrast, treatment with SS31 led to increased cell survival $(\mathrm{P}<0.01 ; \mathrm{n}-4)$, however, concentrations $<10 \mathrm{nM}$ did not improve $661 \mathrm{~W}$ cell survival following oxidant injury.

SS31 significantly attenuates $t$-BHP-induced production of nitrotyrosine and 8-OHdG. When ROS interact with proteins, lipids or DNA, cell dysfunction and death can occur.
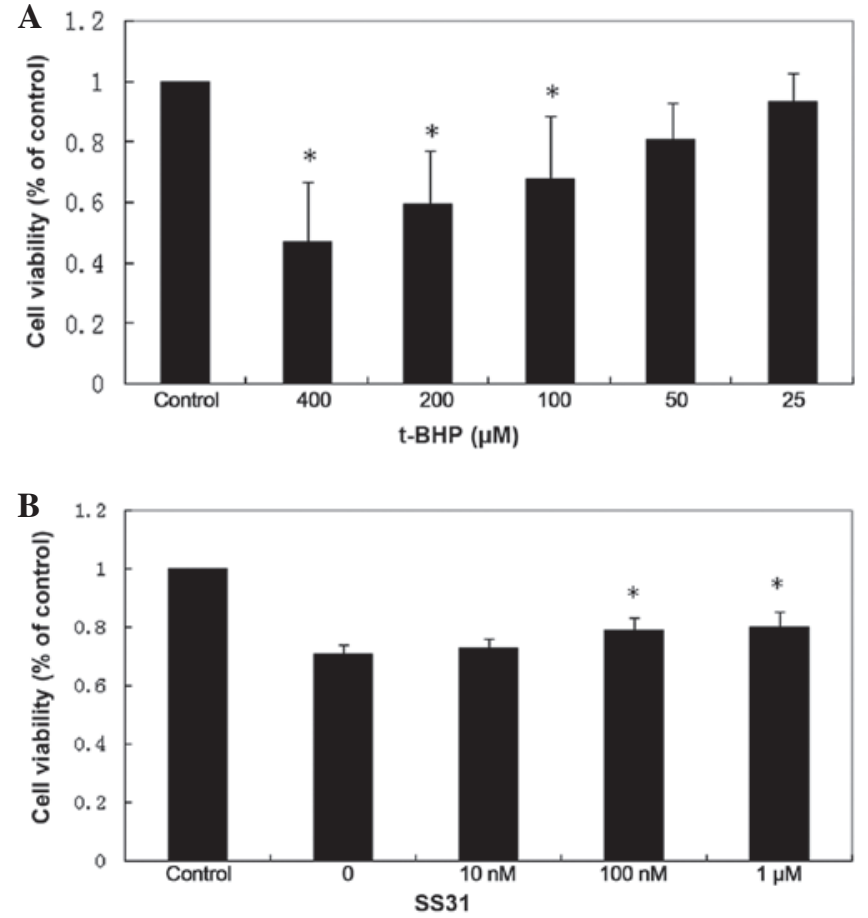

Figure 1. SS31 prevents the decrease in $661 \mathrm{~W}$ cell viability induced by oxidative damage. (A) Concentration-dependent decrease in $661 \mathrm{~W}$ cell viability with increasing t-BHP after $24 \mathrm{~h}$ incubation $\left({ }^{*} \mathrm{P}<0.001\right.$, vs. control). In all cases, the control indicates untreated $661 \mathrm{~W}$ cells. (B) Inhibition of the t-BHP -induced decrease in cell viability by SS31 in the $661 \mathrm{~W}$ cells. Cell viability improved following treatment with SS31 $(10 \mathrm{nM}-1 \mu \mathrm{M})$ for $24 \mathrm{~h}$ $\left({ }^{*} \mathrm{P}<0.01\right.$, vs. t-BHP). Data are presented as the mean \pm standard error of the mean.

Certain sites of macromolecules are particularly susceptible to particular ROS, resulting in specific modifications that act as 'fingerprints', implicating oxidative damage in disease pathogenesis (19). The occurrence of nitrotyrosine residues in proteins is specific for peroxynitrite-induced protein oxidative damage (20). Hydroxyl radicals can also attack guanine at its C-8 position to yield $8-\mathrm{OHdG}$, which serves as another biomarker for DNA oxidative damage. The confocal microscopic images in the present study indicated that treatment of the $661 \mathrm{~W}$ cells with $100 \mathrm{mM}$ t-BHP for $24 \mathrm{~h}$ increased the production of nitrotyrosine and $8-\mathrm{OHdG}$. Concurrent treatment with $100 \mathrm{nM} \mathrm{SS} 31$ prevented the t-BHP-induced accumulation of nitrotyrosine and 8-OHdG (Fig. 2).

SS31 provents t-BHP-induced cell death in $661 \mathrm{~W}$ cells. Morphologically, a significant number of $661 \mathrm{~W}$ cells had detached from the culture dish following treatment with $100 \mathrm{mM}$ t-BHP for $24 \mathrm{~h}$, and those that remained exhibited cell shrinkage and shedding; whereas those co-cultured with $100 \mathrm{nM} \mathrm{SS} 31$ maintained a fairly healthy appearance. Fewer cells were observed in these cultures, partly due to cell death and partly due to cell detachment (Fig. 3A). Following Hoechst staining, the $661 \mathrm{~W}$ cells treated with $100 \mathrm{mM}$ t-BHP for $24 \mathrm{~h}$ exhibited substantial fragmented or condensed nuclei, characteristic of apoptotic cells, whereas few apoptotic nuclei were identified in the control $661 \mathrm{~W}$ cells. The $661 \mathrm{~W}$ cells, which were incubated with $100 \mathrm{nM} \mathrm{SS31}$ had a markedly decreased number of apoptotic nuclei, compared to the t-BHP 

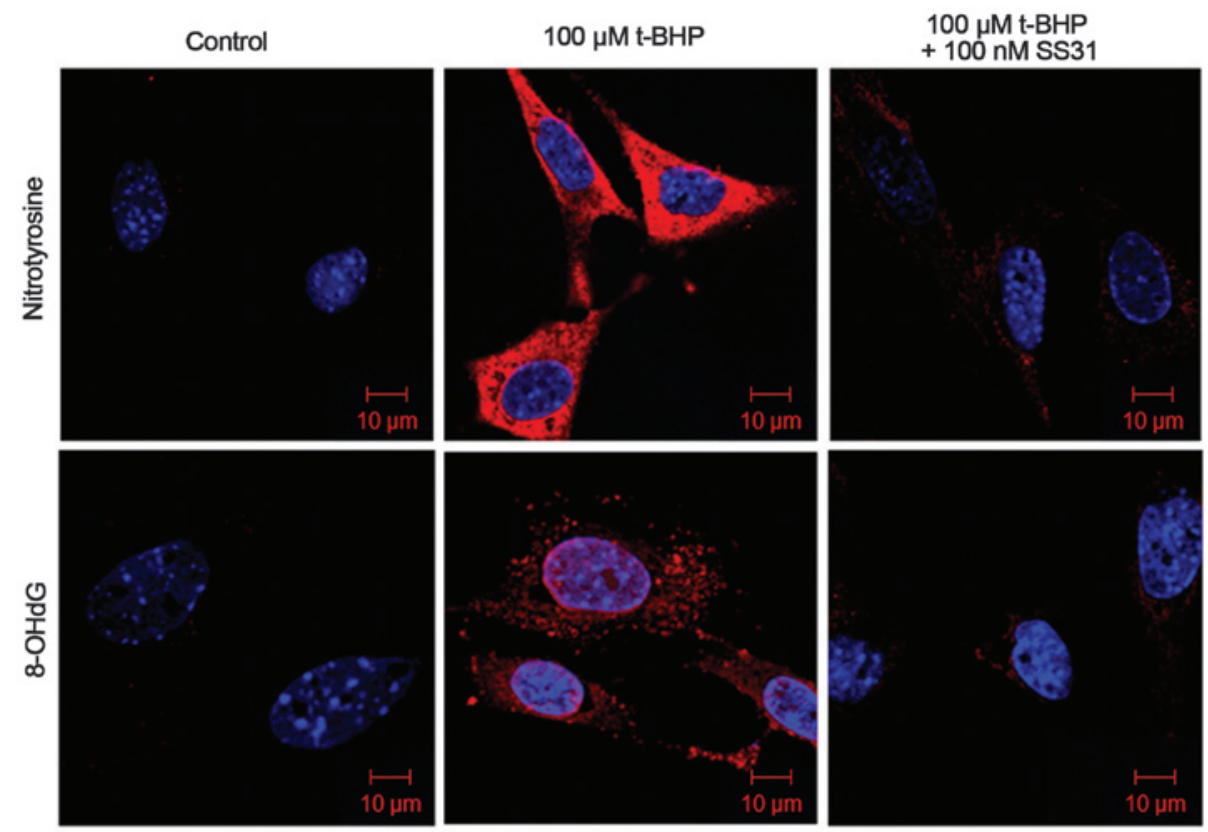

Figure 2. SS31 reduces protein and DNA peroxidation caused by t-BHP. The $661 \mathrm{~W}$ cells were treated with $100 \mu \mathrm{M}$ t-BHP, alone or with $100 \mathrm{nM}$ SS31 for $24 \mathrm{~h}$. The results revealed that treatment of the $661 \mathrm{~W}$ cells with $100 \mu \mathrm{M} \mathrm{t}$-BHP for $24 \mathrm{~h}$ increased the accumulation of nitrotyrosine (red) and 8-OHdG (red) in the nuclei and mitochondrial DNA. Concurrent treatment with $100 \mathrm{nM} \mathrm{SS31}$ prevented the t-BHP-induced accumulation of nitrotyrosine and 8-OHdG. Nuclei (blue) were stained using Hoechst. Immunofluorescence was analyzed using LSM510 META confocal microscopy (magnification, x1,000). 8-OHdG, 8-hydroxydeoxyguanosine.

group, indicating that SS31 protected the $661 \mathrm{~W}$ cells from oxidant-induced $661 \mathrm{~W}$ cell death (Fig. 3B).

In addition, quantitative analysis of annexin $\mathrm{V}$-positive cells was performed in four independent experiments using flow cytometry. In the flow cytometric images, cells negative for PI and annexin V staining were live cells (bottom left); PI-negative, annexin V-positive cells were early apoptotic cells (bottom right); PI-positive, annexin V-positive cells were cells primarily in the late stages of apoptosis (top right); and PI-positive, annexin V-negative cells were necrotic cells (top left). A significant increase in the number of annexin $\mathrm{V}$-positive cells was observed in the $661 \mathrm{~W}$ cells following t-BHP treatment for $24 \mathrm{~h}(20.0 \pm 3.8 \%)$, compared with untreated control cultures $(4.0 \pm 0.6 \% ; \mathrm{P}<0.001)$. The number of annexin V-positive cells decreased dose-dependently to $13.6 \pm 2.6,9.8 \pm 0.5$ and $7.4 \pm 2.0 \%$ in the groups treated with $10 \mathrm{~nm}, 100 \mathrm{~nm}$ and $1 \mu \mathrm{M} \mathrm{SS} 31$, respectively. SS31 at multiple doses demonstrated a significant protective effect against t-BHP $(\mathrm{P}<0.001)$. No significant toxicity was observed over a $24 \mathrm{~h}$ period in the cultures exposed to $1 \mu \mathrm{M} \mathrm{SS} 31$ alone $(2.9 \pm 0.7 \% ; \mathrm{P}=0.429)$, compared with the untreated control cultures (Fig. 3C and D).

SS31 significantly reduces mitochondrial ROS. To further examine the SS31 protective mechanisms, the present study investigated its effect on mitochondrial ROS. MitoSOX ${ }^{\mathrm{TM}}$, a specific dye for mitochondrial ROS, was used to detect mitochondrial ROS. Confocal microscopy was used to localize the oxidative stress-induced increase of ROS production in the mitochondria of the $661 \mathrm{~W}$ cells using MitoSOX ${ }^{\mathrm{TM}}$. Quantitative measurements of the mean fluorescence intensities from the samples demonstrated that $\mathrm{t}$-BHP increased mitochondrial superoxide generation in the $661 \mathrm{~W}$ cells in a dose- and time-dependent manner (Fig. 4A and B). The MitoSOX ${ }^{\mathrm{TM}}$ fluorescence intensity per $\mathrm{mm}^{2}$ cell area increased over time, beginning at $1 \mathrm{~h}(11.0 \pm 2.0 ; \mathrm{P}<0.001$, vs. control). The mitochondrial ROS was markedly increased following incubation with $100 \mu \mathrm{M}$ t-BHP for $1 \mathrm{~h}$, whereas treatment with $100 \mathrm{nM} \mathrm{SS31}$ significantly ameliorated the oxidative stress-induced increase in mitochondrial ROS (Fig. 4C).

SS31 increases $\Delta \Psi m$ during oxidative stress. To determine the involvement of the mitochondrial-mediated pathway in oxidative stress induced cell dysfunction, the present study measured $\Delta \Psi \mathrm{m}$ using flow cytometry, using the cationic membrane potential indicator JC-1. Treatment with $100 \mathrm{nM} \mathrm{SS} 31$ for $4 \mathrm{~h}$ prevented the $100 \mu \mathrm{M} \mathrm{t}$-BHP-induced loss of $\Delta \Psi \mathrm{m}$ in the $661 \mathrm{~W}$ cells (Fig. $5 \mathrm{~A}$ ). Compared with the untreated control cultures, exposure to $100 \mu \mathrm{M} \mathrm{t}-\mathrm{BHP}$ for $4 \mathrm{~h}$ resulted in a rapid decrease in the red/green fluorescence intensity ratio to $51.49 \pm 7.59 \%$ of the control $(\mathrm{P}<0.01$; Fig. 5B). Treatment with $100 \mathrm{nM} \mathrm{SS31}$ significantly increased the red/green fluorescence intensity of the $661 \mathrm{~W}$ cells to $78.18 \pm 6.67 \%$ of the control $(\mathrm{P}<0.05)$, which indicated that the $\Delta \Psi \mathrm{m}$ was restored to baseline.

SS31 inhibits $t$-BHP-induced cytochrome c release. As it is well known that excessive ROS and decreased $\Delta \Psi \mathrm{m}$ can induce apoptotic death, the present study examined the release of mitochondrial cytochrome $c$, an important signaling molecule in apoptosis. This included examining whether oxidative stress induced the release of cytochrome $c$ from the mitochondria and whether the addition of SS31 prevented this release. As shown in Fig. 6, the 661W cells in the control group exhibited an exact overlap of anti-cyto- 
A


B
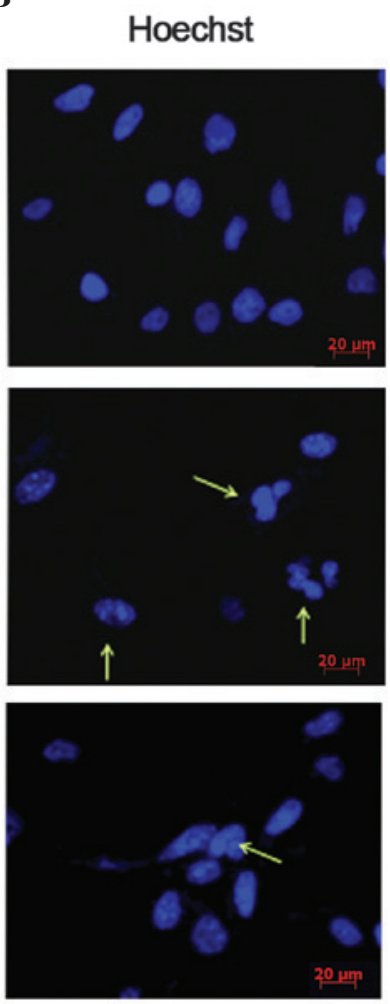

C Flow cytometry

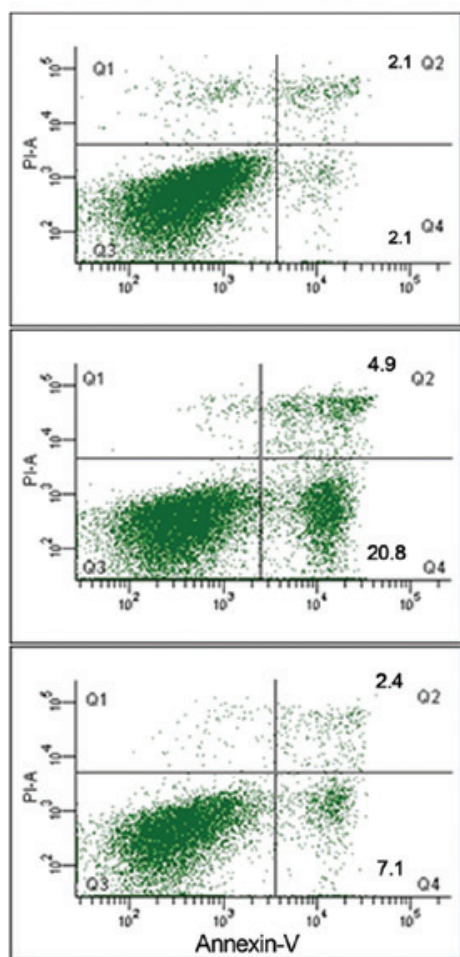

D



Figure 3. SS31 prevents apoptotic nuclei condensation and externalization of membrane phosphatidylserine residue in 661W cells. (A) Phase-contrast light micrographs revealed cells exhibiting a generally unhealthy appearance following treatment with $100 \mu \mathrm{M} \mathrm{t}$-BHP for $24 \mathrm{~h}$, whereas those co-cultured with 100 nM SS31 maintained a relatively healthy appearance. (magnification, x1,000). (B) Representative images of Hoechst-labeled nuclei, condensation of chromatin and apoptotic bodies in the $661 \mathrm{~W}$ cells following damage induced by $100 \mu \mathrm{M} \mathrm{t}$-BHP for $24 \mathrm{~h}$ (arrows). These changes were less visible in the control cells and were markedly improved in the cells treated with $100 \mathrm{nM} \mathrm{SS31}$. (C) Representative flow cytometric images indicated a significant decrease of annexin V-positive cells in the $661 \mathrm{~W}$ cells treated with $100 \mathrm{nM} \mathrm{SS31}$, compared with the cells treated with t-BHP alone for $24 \mathrm{~h}$. (D) Quantitative analysis of annexin V-positive cells was measured in four independent experiments using flow cytometry. The number of annexin V-positive cells decreased in a dose-dependent manner to $13.6 \pm 2.6,9.8 \pm 0.5$ and $7.4 \pm 2.0 \%$ in following treatment with $10 \mathrm{nM}, 100 \mathrm{nM}$ and $1 \mu \mathrm{M}$, respectively $\left({ }^{* *} \mathrm{P}<0.001\right.$, vs. control; ${ }^{*} \mathrm{P}<0.001$, vs. t-BHP). Data are presented as the mean \pm standard error of the mean.

chrome $c$ and HSP60-labeled mitochondrial fluorescence in the confocal micrographs, indicating the co-localization of cytochrome $c$ and mitochondria in the cells. No cytochrome $c$ release was identified from the mitochondria prior to treatment with t-BHP. Following treatment with $100 \mu \mathrm{M}$ t-BHP for $24 \mathrm{~h}$, cytochrome $c$ was observed in the cytoplasm of the 661W cells, and this was not coincident with the mitochondrial labeling, indicating that treatment with t-BHP induced the release of cytochrome $c$ from the mitochondria in the 661W cells (Fig. 6, arrows). By contrast, treatment with 
A

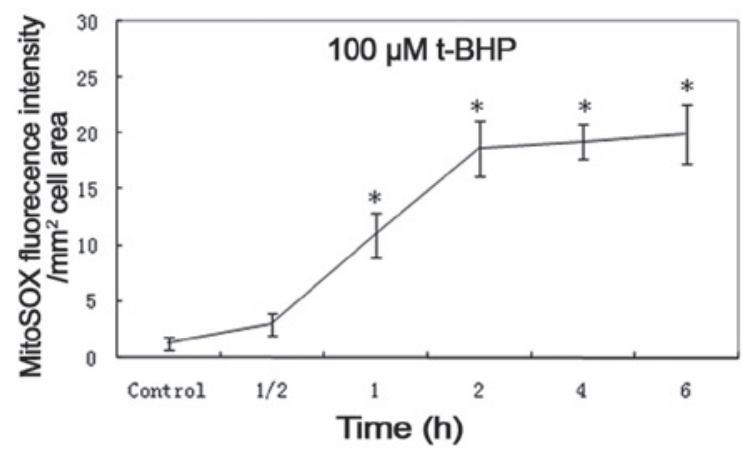

B

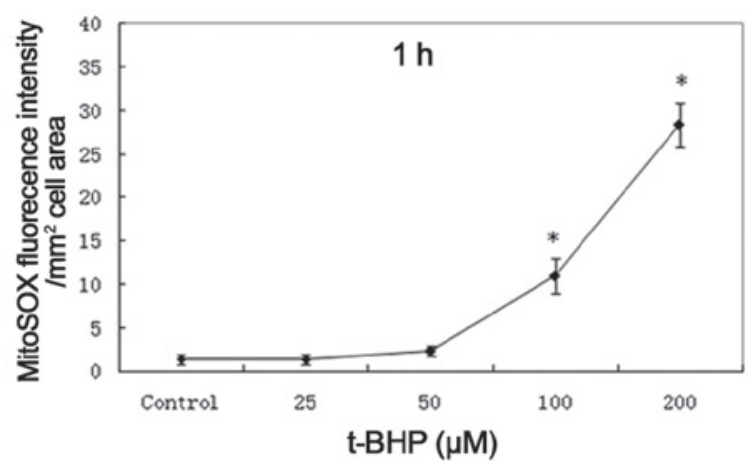

C

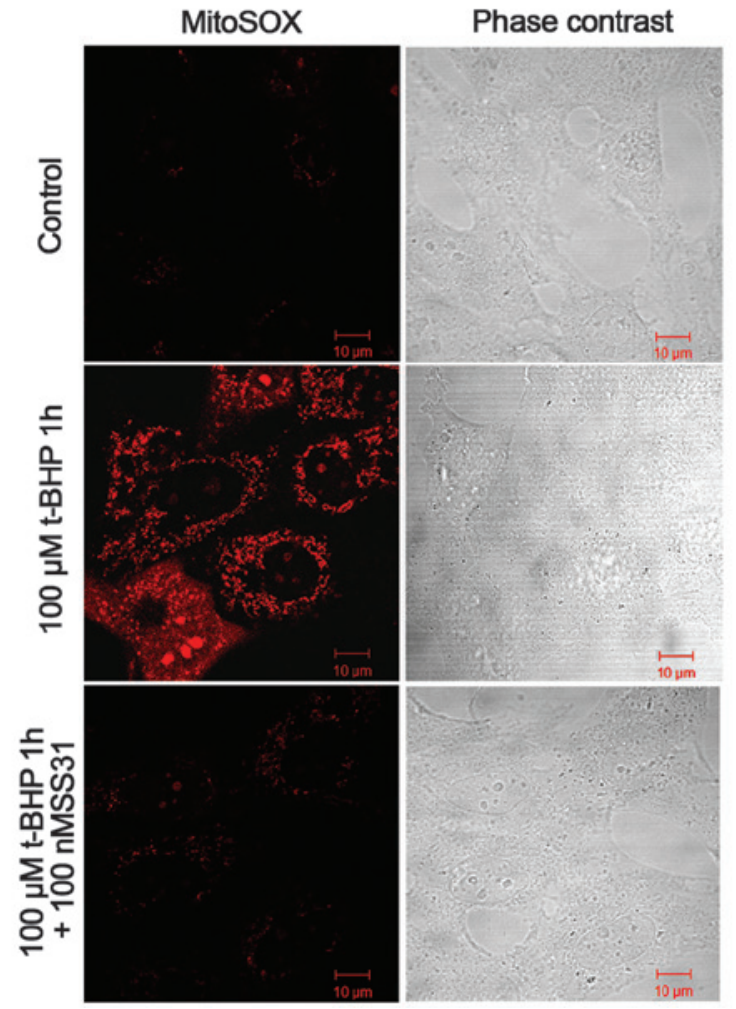

Figure 4. Inhibitory effect of SS31 on t-BHP-induced mitochondrial release of ROS. (A and B) t-BHP increased mitochondrial superoxide generation in the $661 \mathrm{~W}$ cells in a time- and dose-dependent manner. (C) Representative confocal images of $661 \mathrm{~W}$ cells, revealing an increase in mitochondrial MitoSOX $^{\mathrm{TM}}$ fluorescence (red) following treatment with $100 \mu \mathrm{M} \mathrm{t}-\mathrm{BHP}$ for $1 \mathrm{~h}$. Treatment with $100 \mathrm{nM} \mathrm{SS31}$ significantly ameliorated the t-BHPinduced increase in mitochondrial Immunofluorescence was analyzed using LSM510 META confocal microscopy (magnification, x1,000). ROS, reactive oxygen species.

100 nM SS31 inhibited the release of cytochrome $c$ into the cytosol (Fig. 6).

\section{Discussion}

RP is a prevalent cause of blindness, caused by a number of different mutations in several different genes (21). Why mutations in genes that are exclusively expressed in rod photoreceptors can cause the death of rod and cone cells remains to be elucidated, however, it is likely to be multifactorial and it has been hypothesized that oxidative stress-associated photoreceptor injury is important (3). The retina is particularly prone to oxidative damage due to its relatively high oxygen consumption and its constant exposure to light $(5,22)$. Cytotoxic levels of ROS have been found in ocular tissues in vivo, and can be produced during photoreceptor outer segment phagocytosis by the RPE cells (23). In an rd1 mouse model of RP, oxidative damage in the outer retina results in gradual cone cell death (24).

The $661 \mathrm{~W}$ cell line, isolated from transgenic mice by Al-Ubaidi MR, expresses photoreceptor cell markers, including opsin, arrestin, phosphodiesterase, transducin, phosducin, recoverin and IRBP $(25,26)$. However, compared with in vivo photoreceptor cells, $661 \mathrm{~W}$ cells do not express outer segment structural proteins, including RPE65, peripherin/rds and ROM1, which support the cone origin of 661W cells (26). In addition, $661 \mathrm{~W}$ cells have been maintained in culture for $>60$ passages with no apparent slowing of mitotic activity or loss of photoreceptor-specific markers (27), and $661 \mathrm{~W}$ cells grow to confluence at $\sim 2$ days culture with a doubling rate of 1.1 days (28). The patterns of expression of cone opsin and arrestin are not modulated by treatment with factors that stimulate differentiation, including retinoic acid and hydrocortisone. In addition, $661 \mathrm{~W}$ cells have more cytoplasm, a characteristic usually used by pathologists to assess the differentiation status of tumor cells $(29,30)$. Therefore, the $661 \mathrm{~W}$ cell line has been demonstrated as a valuable tool for in vitro investigations of photoreceptor cell biology and function.

t-BHP is a membrane-permeant oxidant, which has been used extensively as a model of oxidative stress in different systems $(31,32)$. Similar to previous studies, the present study found that $\mathrm{t}-\mathrm{BHP}$ causes apoptosis of $661 \mathrm{~W}$ cells, demonstrated by DNA fragmentation and condensation of nuclei at low doses. When concentrations of $\mathrm{t}-\mathrm{BHP}$ are $\geq 400 \mu \mathrm{M}$, the percentage of cell necrosis is markedly increased, rather than apoptosis (data not shown). In the present study, concentrations of SS31 between $10 \mathrm{nM}$ and $1 \mu \mathrm{M}$ are necessary for protection against oxidative damage. Although oxidant-induced cell death can be prevented by a number antioxidants, none have been observed to be effective at concentrations $<1 \mu \mathrm{M}$. In the present study, apoptosis of the $661 \mathrm{~W}$ cells induced by t-BHP was largely inhibited by SS31 treatment at a concentration of $100 \mathrm{nM}$. Additionally, $1 \mu \mathrm{M}$ SS31 had no cytotoxic effect in the absence of t-BHP. Previous studies on different cell types also demonstrated a therapeutic concentration range of 0.1-100 nM for SS31 $(12,14,33)$.

Natural antioxidants, including coenzyme Q $(\mathrm{CoQ})$, vitamin $\mathrm{E}$ and lipoic acid have protective effects in mouse models of Parkinson's disease (PD), ALS, and AD (34-36). It has been reported that patients with RP, who take natural antioxidants, including vitamin $\mathrm{A}$, vitamin $\mathrm{E}$ and docosahexaenoic acid (DHA) exhibited slower declines in ERG amplitudes $(37,38)$. However, high doses of vitamin E may be harmful (39). Antioxidants generally require concentrations 
A

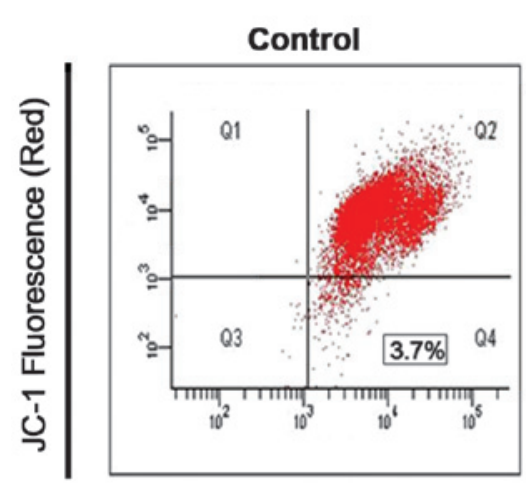

$100 \mu \mathrm{M} \mathrm{t}-\mathrm{BHP} 4 \mathrm{~h}$

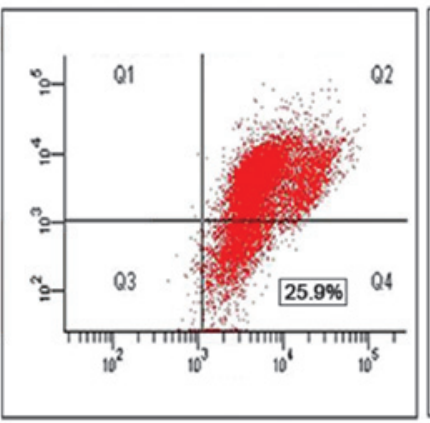

$100 \mu \mathrm{M}$ t-BHP $+100 \mathrm{nM}$ SS31 $4 \mathrm{~h}$

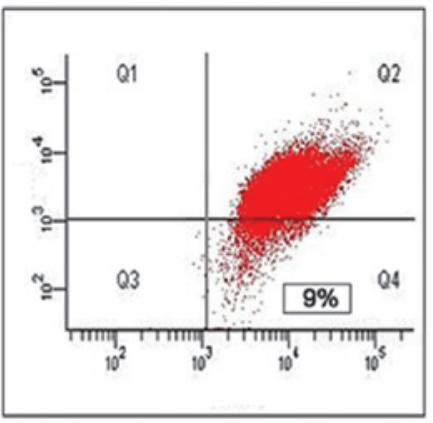

JC-1 Fluorescence (Green)

B



Figure 5. Elevation of $\Delta \Psi \mathrm{m}$ in $661 \mathrm{~W}$ cells by SS31. (A) Treatment with $100 \mathrm{nM} \mathrm{SS31}$ for $4 \mathrm{~h}$ increased the $\Delta \Psi \mathrm{m}$ in the $100 \mu \mathrm{M}$ t-BHP-treated $661 \mathrm{~W}$ cells, demonstrated using flow cytometric analysis. (B) Quantitative analysis of the relative ratio of red/green fluorescence intensity of mitochondrial staining. Treatment with $100 \mathrm{nM} \mathrm{SS31}$ significantly increased the red/green fluorescence intensity of the $661 \mathrm{~W}$ cells $\left(78.18 \pm 6.67 \%\right.$ of the control; ${ }^{* * *} \mathrm{P}<0.05$, vs. t-BHP; ${ }^{*} \mathrm{P}<0.05$, vs. control). Data are presented as the mean \pm standard error of the mean. $\Delta \Psi \mathrm{m}$, mitochondrial membrane potential.

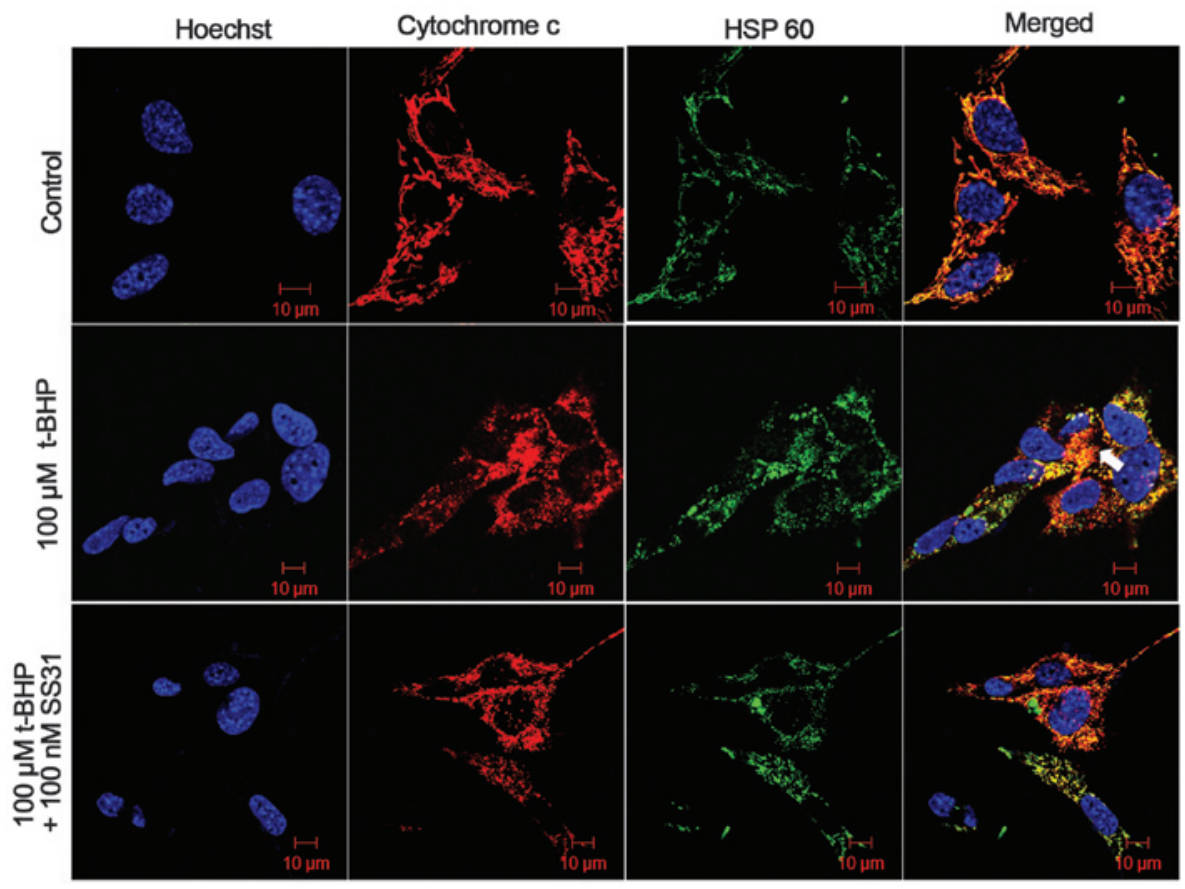

Figure 6. Effect of SS31 on the t-BHP-induced release of cytochrome $c$. The $661 \mathrm{~W}$ cells were subjected to double immunofluorescence antibody staining using mouse anti-cytochrome $c$ antibody (red) and rabbit anti-HSP60 antibody (green). Nuclei were demarcated using Hoechst staining (blue). The overlay of all three types of staining (yellow indicates combination of red and green) is shown in the Merged column. Immunofluorescence was analyzed using confocal microscopy (magnification, $\mathrm{x} 1,000$ ). Arrows indicate the releasing of cytochrome $c$ from the mitochondria in the apoptotic cell. 
of at least $100 \mathrm{mM}$ to reduce oxidative cell death (40). MitoQ has been observed to inhibit $\mathrm{H}_{2} \mathrm{O}_{2}$-induced apoptosis at $1 \mathrm{mM}$, however, concentrations $>10 \mathrm{mM}$ caused cytotoxicity (41). By contrast, SS31 are particularly potent in reducing intracellular ROS and preventing cell death following t-BHP treatment, with a half maximal effective concentration in the $\mathrm{nM}$ range (12). Another possible reason for the lack of efficacy of natural antioxidant is their difficulty in penetrating the blood-brain barrier. It has been reported that treatment with CoQ for 2 months failed to increase brain levels of CoQ (42). Furthermore, certain antioxidants may not reach the relevant sites of free radical generation. Large proteins, including SOD and catalase, do not penetrate cell membranes, and CoQ and Vitamin E are lipophilic, tending to be retained in cell membranes and, therefore, ineffective against intracellular ROS (11). SS31 represents a novel approach with targeted delivery to the inner mitochondrial membrane, containing an amino acid sequence that allows it to freely penetrate cell membranes. Therefore, it has been observed to be taken into cells in a potential-independent, non-saturable manner, even if $\Delta \Psi \mathrm{m}$ is compromised and does cause mitochondrial depolarization, even at $1 \mathrm{mM}(11,32)$.

In the present study, to investigate the effects of oxidative stress, $661 \mathrm{~W}$ cells were stimulated with various concentrations of t-BHP. The results revealed that SS31 at concentrations of $100 \mathrm{nM}$, which inhibited t-BHP-induced cell damage and apoptosis, also prevented intracellular ROS production, nitrotyrosine formation and cytochrome $c$ release. The detailed mechanism by which SS31 protects against oxidative damage remains to be elucidated. By reducing mitochondrial ROS, SS31 is able to prevent opening of the mitochondrial permeability transition pore, prevent mitochondrial swelling and reduce the release of cytochrome $c$ in response to high $\mathrm{Ca}^{2+}$ overload (12). SS31 also protects against $\mathrm{H}_{2} \mathrm{O}_{2}$-induced mitochondrial depolarization in immortalized human trabecular meshwork and glaucomatous human trabecular meshwork cell lines by inhibiting the activation of caspase 3 (33). Our previous study demonstrated that SS31 attenuates the effects of high glucose-induced injuries in human retinal endothelial cells by decreasing the production of ROS, preventing the release of cytochrome $c$ from the mitochondria, decreasing the expression of caspase-3 and increasing the expression of thioredoxin 2 (Trx-2) (43). In addition, SS31 can protect retinal structures and inhibit breakdown of the inner blood retinal barrier by increasing the expression levels of Trx-2 and B-cell lymphoma (Bcl)-2, and decreasing the expression levels of p53, nuclear factor- $\kappa \mathrm{B}, \mathrm{B}$-cell-associated $\mathrm{X}$ protein and caspase-3 in the retina of diabetic rats (44).

In conclusion, the present study demonstrated that SS31 prevented the intracellular production of ROS and revealed significant antioxidant and anti-apoptotic effects on $661 \mathrm{~W}$ cells. Further investigations are required to elucidate the mechanism underlying SS31 and to evaluate its protective effect in RP animal models.

\section{Acknowledgements}

This study was supported by grants from National Basic Research Development Program of China (973 program: no. 2013CB967000) and the National Natural Science
Foundation of China to Professor Yan Luo (no. 81371020) and Dr Xiaobo Zhu (no. 81271012).

\section{References}

1. Portera-Cailliau C, Sung CH, Nathans J and Adler R: Apoptotic photoreceptor cell death in mouse models of retinitis pigmentosa. Proc Natl Acad Sci USA 91: 974-978, 1994.

2. Chang GQ, Hao Y and Wong F: Apoptosis: final common pathway of photoreceptor death in rd, rds and rhodopsin mutant mice. Neuron 11: 595-605, 1993.

3. Shen J, Yang X, Dong A, et al: Oxidative damage is a potential cause of cone cell death in retinitis pigmentosa. J Cell Physiol 203: 457-464, 2005.

4. Komeima K, Rogers BS, Lu L and Campochiaro PA: Antioxidants reduce cone cell death in a model of retinitis pigmentosa. Proc Natl Acad Sci USA 103: 11300-11305, 2006.

5. Yu DY, Cringle SJ, Su EN and Yu PK: Intraretinal oxygen levels before and after photoreceptor loss in the RCS rat. Invest Ophthalmol Vis Sci 41: 3999-4006, 2000.

6. Rotstein NP, Politi LE, German OL and Girotti R: Protective effect of docosahexaenoic acid on oxidative stress-induced apoptosis of retina photoreceptors. Invest Ophthalmol Vis Sci 44: 2252-2259, 2003.

7. Simon HU, Haj-Yehia A and Levi-Schaffer F: Role of reactive oxygen species (ROS) in apoptosis induction. Apoptosis 5: 415-418, 2000.

8. Herrera B, Alvarez AM, Sanchez A, et al: Reactive oxygen species (ROS) mediates the mitochondrial-dependent apoptosis induced by transforming growth factor (beta) in fetal hepatocytes. FASEB J 15: 741-751, 2001.

9. Li N, Ragheb K, Lawler G, et al: Mitochondrial complex I inhibitor rotenone induces apoptosis through enhancing mitochondrial reactive oxygen species production. J Biol Chem 278: 8516-8525, 2003.

10. Palanivel K, Kanimozhi V, Kadalmani B and Akbarsha MA: Verrucarin A induces apoptosis through ROS-mediated EGFR/MAPK/Akt signaling pathways in MDA-MB-231 breast cancer cells. J Cell Biochem 115: 2022-2032, 2014.

11. Szeto HH: Mitochondria-targeted peptide antioxidants: novel neuroprotective agents. AAPS J 8: E521-E531, 2006.

12. Zhao K, Zhao GM, Wu D, et al: Cell-permeable peptide antioxidants targeted to inner mitochondrial membrane inhibit mitochondrial swelling, oxidative cell death and reperfusion injury. J Biol Chem 279: 34682-34690, 2004.

13. Wu D, Soong Y, Zhao GM and Szeto HH: A highly potent peptide analgesic that protects against ischemia-reperfusion-induced myocardial stunning. Am J Physiol Heart Circ Physiol 283: H783-H791, 2002.

14. Cho S, Szeto HH, Kim E, Kim H, Tolhurst AT and Pinto JT: A novel cell-permeable antioxidant peptide, SS31, attenuates ischemic brain injury by down-regulating CD36. J Biol Chem 282: 4634-4642, 2007.

15. Calkins MJ, Manczak M, Mao P, Shirendeb U and Reddy PH: Impaired mitochondrial biogenesis, defective axonal transport of mitochondria, abnormal mitochondrial dynamics and synaptic degeneration in a mouse model of Alzheimer's disease. Hum Mol Genet 20: 4515-4529, 2011.

16. Petri S, Kiaei M, Damiano M, et al: Cell-permeable peptide antioxidants as a novel therapeutic approach in a mouse model of amyotrophic lateral sclerosis. J Neurochem 98: 1141-1148, 2006.

17. Pellicciari C, Bottone MG and Biggiogera M: Detection of apoptotic cells by annexin V labeling at electron microscopy. Eur J Histochem 41: 211-216, 1997.

18. Chazotte B: Labeling mitochondria with JC-1. Cold Spring Harb Protoc 2011: 2011.

19. Soskic V, Groebe K and Schrattenholz A: Nonenzymatic posttranslational protein modifications in ageing. Exp Gerontol 43: 247-257, 2008.

20. Schulz JB, Matthews RT, Muqit MM, Browne SE and Beal MF: Inhibition of neuronal nitric oxide synthase by 7-nitroindazole protects against MPTP-induced neurotoxicity in mice. J Neurochem 64: 936-939, 1995.

21. Hartong DT, Berson EL and Dryja TP: Retinitis pigmentosa. Lancet 368: 1795-1809, 2006.

22. Braun RD, Linsenmeier RA and Goldstick TK: Oxygen consumption in the inner and outer retina of the cat. Invest Ophthalmol Vis Sci 36: 542-554, 1995. 
23. Maslim J, Valter K, Egensperger R, Holländer H and Stone J: Tissue oxygen during a critical developmental period controls the death and survival of photoreceptors. Invest Ophthalmol Vis Sci 38: 1667-1677, 1997.

24. Sanz MM, Johnson LE, Ahuja S, Ekstrom PA, Romero J and van Veen T: Significant photoreceptor rescue by treatment with a combination of antioxidants in an animal model for retinal degeneration. Neuroscience 145: 1120-1129, 2007.

25. al-Ubaidi MR, Font RL, Quiambao AB, et al: Bilateral retinal and brain tumors in transgenic mice expressing simian virus 40 large $\mathrm{T}$ antigen under control of the human interphotoreceptor retinoid-binding protein promoter. J Cell Biol 119: 1681-1687, 1992

26. Tan E, Ding XQ, Saadi A, Agarwal N, Naash MI and Al-Ubaidi MR: Expression of cone-photoreceptor-specific antigens in a cell line derived from retinal tumors in transgenic mice. Invest Ophthalmol Vis Sci 45: 764-768, 2004.

27. Sanvicens N and Cotter TG. Ceramide is the key mediator of oxidative stress-induced apoptosis in retinal photoreceptor cells. J Neurochem 98: 1432-1444, 2006.

28. Crawford MJ, Krishnamoorthy RR, Rudick VL, et al: Bcl-2 overexpression protects photooxidative stress-induced apoptosis of photoreceptor cells via NF-kappaB preservation. Biochem Biophys Res Commun 281: 1304-1312, 2001.

29. Li A, Zhu X and Craft CM: Retinoic acid upregulates cone arrestin expression in retinoblastoma cells through a Cis element in the distal promoter region. Invest Ophthalmol Vis Sci 43: 1375-1383, 2002.

30. Kyritsis A, Joseph G and Chader GJ: Effects of butyrate, retino and retinoic acid on human Y-79 retinoblastoma cells growing in monolayer cultures. J Natl Cancer Inst 73: 649-654, 1984.

31. Nieminen AL, Byrne AM, Herman B and Lemasters JJ: Mitochondrial permeability transition in hepatocytes induced by t-BuOOH: $\mathrm{NAD}(\mathrm{P}) \mathrm{H}$ and reactive oxygen species. Am J Physiol 272: C1286-C1294, 1997.

32. ZhaoK, Luo G, GiannelliS and SzetoHH: Mitochondria-targeted peptide prevents mitochondrial depolarization and apoptosis induced by tert-butyl hydroperoxide in neuronal cell lines. Biochem Pharmacol 70: 1796-1806, 2005.

33. Chen M, Liu B, Gao Q, Zhuo Y and Ge J: Mitochondria-targeted peptide MTP-131 alleviates mitochondrial dysfunction and oxidative damage in human trabecular meshwork cells. Invest Ophthalmol Vis Sci 52: 7027-7037, 2011
34. Veldink JH, Kalmijn S, Groeneveld GJ, et al: Intake of polyunsaturated fatty acids and vitamin $\mathrm{E}$ reduces the risk of developing amyotrophic lateral sclerosis. J Neurol Neurosurg Psychiatry 78: 367-371, 2007.

35. Sikorska M, Lanthier P, Miller H, et al: Nanomicellar formulation of coenzyme Q10 (Ubisol-Q10) effectively blocks ongoing neurodegeneration in the mouse 1-methyl-4-phenyl-1,2,3,6-tetrahydropyridine model: potential use as an adjuvant treatment in Parkinson's disease. Neurobiol Aging 35: 2329-2346, 2014.

36. Maczurek A, Hager K, Kenklies M, et al: Lipoic acid as an anti-inflammatory and neuroprotective treatment for Alzheimer's disease. Adv Drug Deliv Rev 60: 1463-1470, 2008.

37. Fielder AR: A randomized trial of vitamin A and vitamin $\mathrm{E}$ supplementation for retinitis pigmentosa. Arch Ophthalmol 111: 1463; Author Reply 1463-1466, 1993.

38. Berson EL, Rosner B, Sandberg MA, et al: Further evaluation of docosahexaenoic acid in patients with retinitis pigmentosa receiving vitamin A treatment: subgroup analyses. Arch Ophthalmol 122: 1306-1314, 2004

39. Miller ER III, Pastor-Barriuso R, Dalal D, Riemersma RA, Appel LJ and Guallar E: Meta-analysis: high-dosage vitamin E supplementation may increase all-cause mortality. Ann Intern Med 142: 37-46, 2005

40. Jauslin ML, Meier T, Smith RA and Murphy MP: Mitochondria-targeted antioxidants protect Friedreich Ataxia fibroblasts from endogenous oxidative stress more effectively than untargeted antioxidants. FASEB J 17: 1972-1974, 2003.

41. Kelso GF, Porteous CM, Coulter CV, et al: Selective targeting of a redox-active ubiquinone to mitochondria within cells: antioxidant and antiapoptotic properties. J Biol Chem 276: 4588-4596, 2001.

42. Beal MF and Matthews RT: Coenzyme Q10 in the central nervous system and its potential usefulness in the treatment of neurodegenerative diseases. Mol Aspects Med 18 (Suppl): 169-179, 1997.

43. Li J, Chen X, Xiao W, et al: Mitochondria-targeted antioxidant peptide SS31 attenuates high glucose-induced injury on human retinal endothelial cells. Biochem Biophys Res Commun 404: 349-356, 2011.

44. Huang J, Li X, Li M, et al: Mitochondria-targeted antioxidant peptide SS31 protects the retinas of diabetic rats. Curr Mol Med 13: 935-945, 2013. 